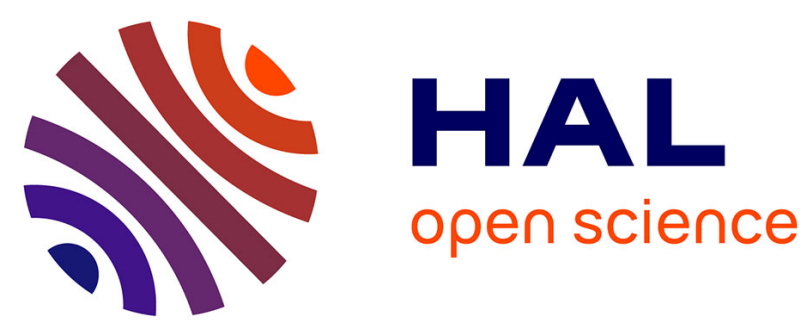

\title{
Direct lead isotopic analysis of bioethanol by means of multi-collector ICP-mass spectrometry with a total consumption sample introduction system
}

Carlos Sánchez, Eduardo Bolea-Fernández, Marta Costas-Rodríguez, Charles-Philippe Lienemann, José-Luis Todolí, Frank Vanhaecke

\section{To cite this version:}

Carlos Sánchez, Eduardo Bolea-Fernández, Marta Costas-Rodríguez, Charles-Philippe Lienemann, José-Luis Todolí, et al.. Direct lead isotopic analysis of bioethanol by means of multi-collector ICP-mass spectrometry with a total consumption sample introduction system. Journal of Analytical Atomic Spectrometry, 2018, 33 (3), pp.481 - 490. 10.1039/C8JA00020D . hal-01859537

\section{HAL Id: hal-01859537 \\ https://hal-ifp.archives-ouvertes.fr/hal-01859537}

Submitted on 22 Aug 2018

HAL is a multi-disciplinary open access archive for the deposit and dissemination of scientific research documents, whether they are published or not. The documents may come from teaching and research institutions in France or abroad, or from public or private research centers.
L'archive ouverte pluridisciplinaire HAL, est destinée au dépôt et à la diffusion de documents scientifiques de niveau recherche, publiés ou non, émanant des établissements d'enseignement et de recherche français ou étrangers, des laboratoires publics ou privés. 


\section{Direct lead isotopic analysis of bioethanol by means of multi-collector ICP-mass spectrometry with a total consumption sample introduction system}

Carlos Sánchez ${ }^{\mathrm{a}, \mathrm{b}}$, Eduardo Bolea-Fernández ${ }^{\mathrm{b}}$, Marta Costas-Rodríguez ${ }^{\mathrm{b}}$, CharlesPhilippe Lienemann ${ }^{c}$, Jose-Luis Todolí ${ }^{a}$, Frank Vanhaecke ${ }^{\mathrm{b} *}$

aniversity of Alicante, Department of Analytical Chemistry, Nutrition and Food Sciences, P.O. Box 99, 03080 Alicante, Spain.

${ }^{b}$ Ghent University, Department of Chemistry, Atomic \& Mass Spectrometry - A\&MS research unit, Campus Sterre, Krijgslaan 281-S12, 9000 Ghent, Belgium.

' IFP Energies Nouvelles, Rond-point de l'échangeur de Solaize, BP 3, 69360 Solaize, France.

*Corresponding author (email: Frank.Vanhaecke@UGent.be) 


\section{Abstract}

A method has been developed for the direct (no sample pre-treatment and/or isolation of the target analyte from the sample matrix) lead isotopic analysis of bioethanol samples via multicollector inductively coupled plasma-mass spectrometry (MC-ICP-MS). A total consumption sample introduction system, the so-called high-temperature Torch-Integrated Sample Introduction System (hTISIS), equipped with a PFA micro-nebulizer and a heated small-volume spray chamber, has been used for (i) reducing the analyte concentration required for obtaining accurate and precise lead isotope ratio results and (ii) mitigating the effect of the ethanolwater ratio on the extent of mass bias.

The results obtained when using the hTISIS have been compared to those obtained with a more conventional sample introduction system, i.e. a micro-nebulizer mounted onto a cyclonic spray chamber at room temperature. The performance of both introduction systems has been assessed for two different plasma interfaces. The Pt standard sampling cone has been combined with an X-type or H-type skimmer cone, respectively. The sensitivity achieved with the hTISIS was between 3- and 7.5-fold higher, depending on the ethanol-water ratio, than that with the conventional sample introduction system, thus permitting accurate lead isotope ratios to be obtained at lower concentration levels without degradation of the precision. The external precisions, reported as 2 times the relative standard deviation (2RSD), for ${ }^{207} \mathrm{~Pb} /{ }^{206} \mathrm{~Pb}$ and ${ }^{208} \mathrm{~Pb} /{ }^{206} \mathrm{~Pb}$ were $0.007 \%$ and $0.008 \%$, respectively, whereas the internal precision was $0.007 \%$ (2 RSD) for both isotope ratios.

The effects of ethanol content and the hTISIS temperature on the extent of mass bias have been evaluated for the four instrument setups (different sample introduction system/skimmer cone type combinations). The combination of (i) internal correction using NIST SRM 997 thallium as an internal standard relying on Russell's law and (ii) external correction using NIST SRM 981 - lead, prepared in 75\% ethanol, in a sample-standard bracketing (SSB) approach was used for mass bias correction. Although bioethanol samples may contain different amounts of water, the correction described above enabled adequate correction for mass bias in ethanolwater matrices with a water content of 0 to $40 \%$ and thus, also for actual bioethanol samples, when using the hTISIS operated at $125^{\circ} \mathrm{C}$ and an X-type skimmer cone.

The methodology has been successfully validated by means of lead isotopic analysis of bioethanol samples spiked with a lead standard previously characterized isotopically. Finally, as a proof of concept, actual bioethanol samples have been analyzed and significant differences in the lead isotope ratios have been observed.

Keywords: Lead isotope ratios, direct isotopic analysis, ICP-MS interface, total sample consumption system, bioethanol. 


\section{Introduction}

Biofuels are currently considered an interesting alternative energy source as they bring about a lower burden on human health and the environment than fossil fuels, while they could offer a solution for the increasing demand of energy in view of the limited petroleum stock. ${ }^{1-3}$ Among the variety of biofuels available, bioethanol has emerged as one of the most promising products, as its use involves a reduction of the emission of greenhouse gases (GHG), such as $\mathrm{CO}_{2}, \mathrm{CH}_{4}$ and $\mathrm{N}_{2} \mathrm{O}$, up to $75 \%$ compared with fossil fuels. ${ }^{1-5}$

Bioethanol can be used in its pure form within modified spark-ignition engines or blended with petrol (ethanol-fuel). In the latter case, the bioethanol in the blend acts as an efficient octaneboosting agent, thereby substituting for toxic chemical additives, such as methyl tert-buthyl ether (MTBE). ${ }^{1,3,6}$

As a result of the advantages of bioethanol compared to fossil fuels, its production and consumption have grown exponentially during the last two decades. ${ }^{7}$ Different biofuel generations have appeared along this time. The first-generation bioethanol is the alcoholic product generated from sugars, seeds or starch by microorganisms. ${ }^{6}$ However, the fuel-food competition is regarded an important ethical issue impeding the global implementation of this first-generation bioethanol. ${ }^{1,6,8}$ The second-generation bioethanol overcomes this problem, since the raw material used is based on whole plant biomass or on non-edible crop production. ${ }^{2,6,9}$ However, the production process is complex and the yield reached is lower than that of the first-generation processes. ${ }^{6}$

The final product generated from these processes contains mainly ethanol and a variable percentage of water. It may also contain organic and inorganic pollutants (including metals) at minor and trace levels. Nowadays, only limited regulations for the levels of metals in bioethanol samples exist ${ }^{10,11}$, although recent works paid attention to the analysis of this type of samples via inductively coupled plasma-optical emission spectrometry (ICP-OES) ${ }^{4,12}$ or inductively coupled plasma-mass spectrometry (ICP-MS) $)^{4,13}$. However, not only elemental analysis of bioethanol is relevant, e.g., for the purpose of quality control, but also isotopic analysis can provide valuable information, e.g., related to the geographical provenance and type of raw material used for its production.

In general, the conventional methodology used for high-precision isotopic analysis via multicollector inductively coupled plasma-mass spectrometry (MC-ICP-MS) involves the isolation of the analyte from the matrix using off-line chromatographic methods. ${ }^{14-16}$ This approach reduces the occurrence of spectral interference and allows a reliable correction for the mass bias caused by instrumental mass discrimination. However, this procedure is laborious, timeconsuming and costly, and it can generate a considerable amount of waste. As an alternative, some papers describe the use of high-performance liquid chromatography (HPLC) coupled to MC-ICP-MS for on-line chromatographic separation. ${ }^{17,18}$ Even after analyte isolation, adequate correction for mass bias often involves a combination of internal correction relying on the use of an admixed internal standard and external correction in a sample-standard bracketing approach (SSB). ${ }^{16,19-22}$

High-precision isotopic analysis of $\mathrm{Pb}$ by multi-collector ICP-MS is used for provenancing (determination of the geographical origin) purposes. ${ }^{22-25}$ Lead isotope ratios have been 
determined in fossil fuels and other organic samples ${ }^{26,27}$ using the conventional methodology, involving off-line chromatographic isolation of $\mathrm{Pb}$ from the sample matrix. However, to the best of the authors' knowledge, so far, isotopic analysis has not been performed for biofuels in general, and bioethanol in particular.

This study explored $\mathrm{Pb}$ isotopic analysis of bioethanol, whereby an effort was done to avoid extensive sample pretreatment. The direct introduction of organic samples in a MC-ICP-MS instrument is challenging due to several reasons: the organic matrix can negatively affect the stability of the plasma, while the organic solvents can exert an effect on the extent of mass bias that might not be adequately corrected for due to the difference in matrix composition between the external standard and the sample, thus possibly jeopardizing the accuracy of the results obtained.

The total consumption sample introduction system hTISIS (high-temperature Torch-Integrated Sample Introduction System $)^{28}$ was shown to be able to overcome the main problems related with elemental analysis of organic samples in general, and of fuels and biofuels in particular. The hTISIS operated under optimized conditions can minimize matrix effects caused by ethanol or other organic solvents delivered to the plasma, because the differences in transport efficiency are mitigated or even eliminated. ${ }^{12,13,29,30}$ In addition, the use of the hTISIS contributes to an enhanced plasma stability, since the optimum sample uptake rates used with the hTISIS are lower than those used with the conventional sample introduction systems and, thus, also the volume of sample required for analysis is reduced. Moreover, the sensitivity provided by the hTISIS is generally higher than that with the conventional sample introduction systems. The combination of an hTISIS and MC-ICP-MS has been previously used for carrying out studies in aqueous sample matrices, aiming at improving the sensitivity and/or at reducing the volume of sample required for the analysis. ${ }^{31-35}$ However, its application to direct isotopic analysis of organic samples has not been investigated yet.

The main objective of this work was to explore the analytical capabilities of the hTISIS as a sample introduction system in the direct, i.e. without sample pre-treatment and/or chromatographic separation, isotopic analysis of lead in bioethanol samples via MC-ICP-MS. For this purpose, the effect of various ethanol-water mixtures on the lead isotope ratio results was evaluated for the hTISIS (operated at different temperatures) and a conventional sample introduction system (microconcentric nebulizer and cyclonic spray chamber) coupled to a MCICP-MS unit using two different skimmer cone types ( $\mathrm{X}$ and $\mathrm{H}$-type).

\section{Experimental}

\subsection{Aqueous standards and certified reference materials}

Isotopic reference materials of lead (NIST SRM 981) and thallium (NIST SRM 997) from the National Institute for Standards and Technology (NIST, Gaithersburg, MD, USA), were used for the correction of the mass bias induced by instrumental mass discrimination; they will be referred to along the manuscript as "NIST-Pb" and "NIST-TI", respectively. The isotope ratios reported in the certificate, and thus used for mass bias correction are ${ }^{208} \mathrm{~Pb} /{ }^{206} \mathrm{~Pb}=2.1681 \pm$ $0.0008,{ }^{207} \mathrm{~Pb} /{ }^{206} \mathrm{~Pb}=0.91464 \pm 0.00033,{ }^{208} \mathrm{~Pb} /{ }^{207} \mathrm{~Pb}=2.3704 \pm 0.0009$ and ${ }^{205} \mathrm{Tl} /{ }^{203} \mathrm{Tl}=2.38714$ \pm 0.00101 . 
An in-house standard solution of lead (Inorganic Ventures, Christiansburg, VA, USA, lot D2PB03020) was characterized for its isotopic composition using a conventional approach, i.e. by means of MC-ICP-MS with a conventional sample introduction system relied on $\mathrm{Tl}$ for the internal standardization using NIST-TI and SSB approach using NIST-Pb as standards ${ }^{36}$. This standard solution will be termed "IH-Pb". The lead isotope ratios for $\mathrm{IH}-\mathrm{Pb}$ are ${ }^{208} \mathrm{~Pb} /{ }^{206} \mathrm{~Pb}=$ $2.17616 \pm 0.00019,{ }^{207} \mathrm{~Pb} /{ }^{206} \mathrm{~Pb}=0.92331 \pm 0.00006$ (average $\pm 95 \%$ confidence level for $\mathrm{n}=15$ and $\alpha=0.05$, determined in a $3 \% \mathrm{HNO}_{3}$ matrix).

\subsection{Ethanol-water standards and bioethanol samples}

Different ethanol-water standards containing ethanol concentrations ranging from 10 to $100 \%$ $(\mathrm{v} / \mathrm{v})$ were prepared using ultrapure water (resistivity $\geq 18.2 \mathrm{M} \Omega \mathrm{cm}$ ) obtained from a Direct-Q water purification system (Millipore, Molsheim, France) and absolute ethanol of analytical reagent grade (Fisher Scientific, Waltham, MA, USA). Isotopic reference materials NIST-Pb and NIST-TI were added into the ethanol-water solutions in a 1:1 ratio. Additionally, standards containing $\mathrm{IH}-\mathrm{Pb}$ and NIST-TI were prepared in $50 \%, 75 \%$ and $100 \%$ of ethanol. The $\mathrm{Pb}$ and $\mathrm{TI}$ concentrations added to each ethanolic solution were adapted such as to obtain the same signal intensity in every ethanol-water mixture.

Sample-standard bracketing solutions containing NIST-Pb and NIST-TI in a 1:1 ratio were prepared in $75 \%$ ethanol. The $\mathrm{Pb}: \mathrm{Tl}$ concentration ratio was selected aiming at obtaining signal intensities in the same order of magnitude for $\mathrm{Pb}$ and $\mathrm{Tl}$ isotopes, as it is required for an adequate mass bias correction. The $\mathrm{Pb}$ concentrations at which the isotope ratio measurements were carried out were: (i) $10 \mathrm{~g} \mathrm{~L} \mathrm{~L}^{-1}$ with the hTISIS and X-type skimmer cone; (ii) $15 \mu \mathrm{g} \mathrm{L}^{-1}$ for the conventional introduction system and the X-type skimmer cone; (iii) $40 \mu \mathrm{g}$ $\mathrm{L}^{-1}$ for the hTISIS and the H-type skimmer cone; and (iv) $60 \mu \mathrm{g} \mathrm{L}^{-1}$ for the conventional introduction system and the $\mathrm{H}$-type skimmer cone. The concentrations were different for different sample introduction systems and skimmer cones in order to reach the same signal intensity for the four approaches.

For method validation purposes, seven bioethanol samples containing lead concentrations lower than $0.025 \mu \mathrm{g} \mathrm{L}^{-1}$ were spiked with $5 \mu \mathrm{g} \mathrm{L} \mathrm{L}^{-1}$ of IH-Pb and $5 \mu \mathrm{g} \mathrm{L}^{-1}$ of NIST-TI. Furthermore, lead isotope ratios were measured in six real bioethanol samples. The raw material used for the manufacturing of bioethanol can be of different nature; bioethanol is mainly obtained from sugarcane, wheat, wine alcohol, or biomass (when produced from the latter, it is termed second-generation bioethanol). Some of these samples were dehydrated bioethanol, whereas some of them contained water in a content ranging from approximately 2 to $35 \%$. TI concentration in the samples was below $0.003 \mu \mathrm{g} \mathrm{L}^{-1}$ (method detection limit for thallium quantification-MDL), see section 2.3.

\subsection{Instrumentation and measurements}

An Agilent 7900 ICP-MS Spectrometer (Agilent, Santa Clara, CA, USA) was used for Pb and TI quantification in the bioethanol samples. Lead and thallium standards for external calibration were prepared in $2 \% \mathrm{HNO}_{3}$ by appropriate dilution of a stock solution containing $1 \mathrm{~g} \mathrm{~L}^{-1}$ of $\mathrm{Pb}$ 
(Inorganic ventures) and $1 \mathrm{~g} \mathrm{~L}^{-1}$ of $\mathrm{TI}$ (Inorganic ventures). Intensities for ${ }^{203} \mathrm{Tl},{ }^{205} \mathrm{Tl},{ }^{206} \mathrm{~Pb},{ }^{207} \mathrm{~Pb}$ and ${ }^{208} \mathrm{~Pb}$ were monitored in vented mode (without addition of collision and/or reaction gas).

$\mathrm{Pb}$ and $\mathrm{Tl}$ isotope ratios were measured using a Thermo Scientific (Bremen, Germany) Neptune MC-ICP-MS instrument equipped with a $130 \mathrm{~m}^{3} / \mathrm{h}$ dry interface pump, operated at low mass resolution. All solutions were delivered to the nebulizer by means of a peristaltic pump (Spetec, Erding, Germany) and by using a $0.25-\mathrm{mm}$ id flared-end solvent-resistant tubing (Glass Expansion, Melbourne, Australia).

Samples and standards were introduced into the plasma by means of a PFA nebulizer (Elemental Scientific, Omaha, NE, USA) coupled onto a spray chamber. Two different sample introduction systems were evaluated: (i) an hTISIS with a $9 \mathrm{~cm}^{3}$ single-pass spray chamber and operated at different temperatures ${ }^{12,13,28,29,37}$, and (ii) a cyclonic spray chamber (Elemental Scientific, Omaha, NE, USA) operated at room temperature, as a conventional sample introduction system. The instrument settings and the data acquisition parameters selected are gathered in Table 1. For final method validation and for analysis of the real bioethanol samples, the hTISIS was operated at $125^{\circ} \mathrm{C}$.

Platinum sampling and skimmer cones were used because of the introduction of $\mathrm{O}_{2}$ for adequate handling of the ethanolic solutions. Two different skimmer cone types were tested, the $\mathrm{H}$-type (conventional model) and X-type (providing higher sensitivity). ${ }^{38} \mathrm{~A}$ quartz torch with a $1.0 \mathrm{~mm}$ inner diameter injector was used. A Smart Mass Flow 5850S (Brooks Instruments, Hatfield, PA, USA) mass flow controller, connected to a Brooks Microprocessor Control \& Read Out Unit 0152 (Brooks Instruments, Hatfield, PA, USA), was used for introducing $0.2 \mathrm{~L} \mathrm{~min}^{-1}$ of additional gas ( $20 \%$ of $\mathrm{O}_{2}+80 \%$ of $\mathrm{Ar}$ ) to avoid carbon deposition on the torch and the interface cones. ${ }^{4,13,39}$

Correction for the bias caused by instrumental mass discrimination was accomplished using the combination of internal correction relying on $\mathrm{Tl}$ as an internal standard, followed by external correction in a sample-standard bracketing (SSB) approach. For the internal correction with $\mathrm{Tl}$ as an internal standard, different correction approaches were evaluated: (i) Russell's law $^{16}$, (ii) the method proposed by Woodhead et al. ${ }^{19}$, and (iii) the latter method as further refined by Baxter et al. ${ }^{20}$ An ethanol-water mixture with $75 \%$ ethanol was consistently used as matrix for the SSB standard. In all cases, the Pb signals for the blanks were negligible compared to those for samples and standards $(<0.1 \%)$.

Table 1. Conditions used for isotope ratio measurements (Thermo Scientific Neptune MC-ICPMS)

\begin{tabular}{c|c|c}
\hline \hline \multicolumn{2}{c}{ Instrument settings } & Conventional \\
\hline Introduction system & hTISIS $^{+}$ & 100 \\
\hline Sample uptake rate $\left(\mu \mathrm{L} \mathrm{min}{ }^{-1}\right)$ & 50 & RT \\
\hline Spray chamber temperature $\left.{ }^{\circ} \mathrm{C}\right)$ & 125 & 1300 \\
\hline RF power $(\mathrm{W})$ & 1400 & \multicolumn{2}{c}{0.80} \\
\hline Plasma gas flow rate $\left(\mathrm{L} \mathrm{min}^{-1}\right)$ & \multicolumn{2}{c}{} \\
\hline Auxiliary gas flow rate $\left(\mathrm{L} \mathrm{min}^{-1}\right)$ &
\end{tabular}




\begin{tabular}{|c|c|c|}
\hline \multicolumn{2}{|c|}{ Optimum nebulizer gas flow rate $\left(\mathrm{L} \mathrm{min}^{-1}\right)$} & 0.485 \\
\hline \multicolumn{2}{|c|}{ Additional $\mathrm{O}_{2} / \mathrm{Ar}(20 \% / 80 \%)$ flow rate $\left(\mathrm{L} \mathrm{min}^{-1}\right)$} & 0.20 \\
\hline \multicolumn{2}{|c|}{ Sampling cone } & Standard Pt $1.1 \mathrm{~mm}$ id orifice \\
\hline \multicolumn{2}{|c|}{ Skimmer cone } & $\begin{array}{l}\text { H skimmer Pt } 0.8 \mathrm{~mm} \text { id orifice } \\
\text { X skimmer Pt } 0.8 \mathrm{~mm} \text { id orifice }{ }^{+}\end{array}$ \\
\hline \multicolumn{2}{|c|}{ Lenses settings } & Optimized for maximum $\mathrm{Pb}$ sensitivity \\
\hline \multicolumn{2}{|c|}{ Resolution mode } & Low \\
\hline \multicolumn{3}{|c|}{ Data acquisition parameters } \\
\hline Scan type & \multicolumn{2}{|c|}{ Static; multi-collection } \\
\hline Number of blocks & \multicolumn{2}{|r|}{7} \\
\hline Number of cycles/block & \multicolumn{2}{|r|}{6} \\
\hline Integration time (s) & \multicolumn{2}{|r|}{4.194} \\
\hline Cup configuration & \multicolumn{2}{|c|}{ L3: ${ }^{202} \mathrm{Hg} ; \mathrm{L2}:{ }^{203} \mathrm{Tl} ; \mathrm{L} 1:{ }^{204} \mathrm{~Pb} ; \mathrm{C}:{ }^{205} \mathrm{Tl} ; \mathrm{H1}:{ }^{206} \mathrm{~Pb} ; \mathrm{H2}:{ }^{207} \mathrm{~Pb} ; \mathrm{H3}:{ }^{208} \mathrm{~Pb}$} \\
\hline Resistor on pre-amplifier & \multicolumn{2}{|c|}{$\mathrm{C}, \mathrm{L} 1, \mathrm{~L} 2, \mathrm{~L} 3: 10^{11} \Omega ; \mathrm{H} 1, \mathrm{H} 2, \mathrm{H} 3: 10^{12} \Omega$} \\
\hline
\end{tabular}

${ }^{\dagger}$ Optimum conditions in terms of sensitivity selected for the analysis of bioethanol samples.

$\mathrm{RT}$ : room temperature

\section{Results and discussion}

\subsection{Effect of sample introduction system and skimmer type on the sensitivity}

The use of different sample introduction systems and/or plasma-spectrometer interfaces strongly affects the sensitivity of ICP-MS instruments. In this section, the effects of $(i)$ the Pt skimmer cone type ( $\mathrm{X}$ vs $\mathrm{H}$ ) and (ii) the sample introduction system (conventional vs hTISIS) on the absolute sensitivity of ${ }^{208} \mathrm{~Pb}$ in 10,50 and $100 \%$ ethanol have been evaluated. As can be seen in Figure 1.a., a 5 to 7 -fold improvement in sensitivity was obtained when replacing the $\mathrm{H}$-type by the X-type skimmer cone. This enhancement in sensitivity is caused by the different geometry of the $X$ skimmer cone, which provides a significantly higher ion extraction efficiency from the plasma. ${ }^{40,41}$

Figure 1.b. shows the sensitivity obtained for different ethanol-water matrices using the hTISIS operated at $125^{\circ} \mathrm{C}$ (the optimized temperature, providing maximum sensitivity) and the conventional introduction system using the X-type skimmer cone. It is noteworthy that the use of the hTISIS leads to an enhanced Pb signal sensitivity for all of the ethanol-water standards tested. A 1.6-fold increase was obtained at $100 \%$ ethanol, whereas an improvement factor of 2.3 and 3.7 was found for the $\mathrm{Pb}$ standards in 50 and $10 \%$ of ethanol, respectively. These differences in the enhancement factor can be attributed to the different operation mechanism of the sample introduction systems used. In the case of the hTISIS working under optimum conditions, the analyte transport efficiency is virtually $100 \%$ for any ethanol content. However, the transport efficiency with the conventional sample introduction systems strongly depends on the physical properties of the sample as these define the nebulization efficiency and aerosol droplet size distribution, with the sensitivity increasing with increasing ethanol 
concentration. It needs to be stressed that the hTISIS provided the aforementioned improvement despite working at half of the sample uptake rate than that of the conventional introduction system. Taking this fact into account, the improvement in sensitivity was 3.2-, 4.6and 7.4-fold for $\mathrm{Pb}$ standards in 100, 50 and $10 \%$ of ethanol, respectively. The same trend in the sensitivity was observed for $\mathrm{Tl}$.

Next to this enhancement in sensitivity, with the hTISIS the sensitivity also depends much less on the ethanol concentration of the samples, which is advantageous for the isotopic analysis of bioethanol samples, since these may be characterized by different water contents. ${ }^{12,13}$

Under optimum conditions, the sensitivity was $0.07-0.08 \mathrm{~V}$ per $\mu \mathrm{g} \mathrm{L}^{-1}\left(0.14-0.16 \mathrm{~V} \mathrm{ng}^{-1}\right)$ for ${ }^{208} \mathrm{~Pb}$ and $0.10-0.11 \mathrm{~V}$ per $\mu \mathrm{g} \mathrm{L}^{-1}\left(0.20-0.22 \mathrm{~V} \mathrm{ng}^{-1}\right)$ for ${ }^{205} \mathrm{Tl}$ with amplifiers equipped with a $10^{12} \Omega$ resistor.
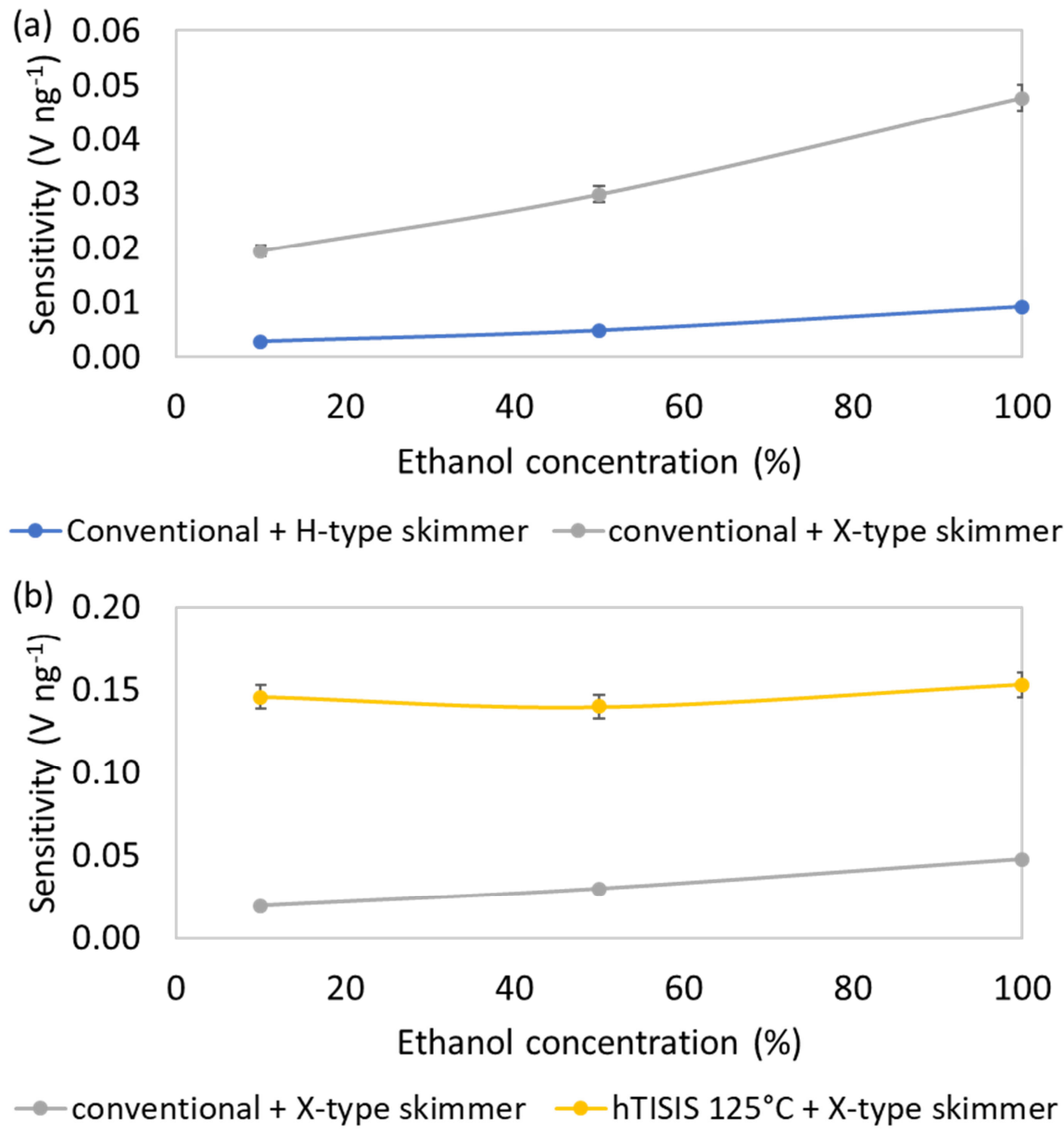

Figure 1. Effect of ICP-MS interface (a) and introduction system (b) on the sensitivity. Volume hTISIS: $500 \mu \mathrm{L}$, volume conventional spray chamber: $1 \mathrm{~mL}$. Error bars $=2 \mathrm{~s}$. 


\subsection{Effect of sample introduction system and skimmer type on the isotope ratio precision and accuracy}

The isotope ratio precision is a crucial parameter for isotopic analysis, since it strongly affects the overall uncertainty associated to each measurement result, and thus, the capability to reveal small variations in the isotopic composition, required for meaningful interpretation of the results.

Before assessing the effect of sample introduction system and skimmer cone type on the isotope ratio precision and accuracy for a given ethanol-water mixture (75\% ethanol), further used as the SSB standard, the possible influence of the ethanol content on the external precision was evaluated by measuring the ${ }^{208} \mathrm{~Pb} /{ }^{206} \mathrm{~Pb}$ and ${ }^{207} \mathrm{~Pb} /{ }^{206} \mathrm{~Pb}$ ratios in NIST-Pb standards prepared in matrices containing ethanol concentrations in the range of 10 to $100 \%$. For such experiment, the concentration of $\mathrm{Pb}$ for the hTISIS was set at $50 \mu \mathrm{g} \mathrm{L}^{-1}$, while for the conventional sample introduction system, the $\mathrm{Pb}$ content was adapted such that a similar signal intensity was observed. No differences (or trend) of isotope ratios precision were observed as a function of the ethanol concentration, with isotope ratio precisions (reported as two times the relative standard deviation - 2RSD) for each standard solution distributed randomly from 0.003 to $0.007 \%$ and from 0.001 to $0.006 \%$ for ${ }^{208} \mathrm{~Pb} /{ }^{206} \mathrm{~Pb}$ and ${ }^{207} \mathrm{~Pb} /{ }^{206} \mathrm{~Pb}$, respectively ( $n=5,2 R S D)$.

Internal and external precisions (Table 2) were evaluated for the four instrumental setups: (i) hTISIS and X-type skimmer cone; (ii) hTISIS and H-type skimmer cone, (iii) cyclonic spray chamber and X-type skimmer cone and, (iv) cyclonic spray chamber and $\mathrm{H}$-type skimmer cone. Internal precision was evaluated by using the relative standard deviation (2RSD) obtained for 42 consecutive measurements of a $\mathrm{Pb}$ standard solution prepared in $75 \%$ ethanol. The concentration of NIST-Pb was adapted for obtaining the same signal intensity with the four instrumental setups used (see Table 2). Significant differences in the precision of ${ }^{208} \mathrm{~Pb} /{ }^{206} \mathrm{~Pb}$ and ${ }^{207} \mathrm{~Pb} /{ }^{206} \mathrm{~Pb}$ ratios were not observed and similar precisions (2RSDs) were obtained for the four approaches, with values ranging from $0.007 \%$ to $0.010 \%$ for ${ }^{208} \mathrm{~Pb} /{ }^{206} \mathrm{~Pb}$ and around $0.007 \%$ for ${ }^{207} \mathrm{~Pb} /{ }^{206} \mathrm{~Pb}$.

External precision was calculated as the relative standard deviation (2RSD) obtained for all measurements of the NIST-Pb standard (prepared in $75 \%$ ethanol) carried out during a complete measurement session $(8 \mathrm{~h}-12 \mathrm{~h})$ for each of the four instrumental approaches. The findings for external precision were similar to those observed for internal precision and no significant differences were noticed between the sample introduction systems and/or skimmer cone types used. Moreover, precisions obtained for ${ }^{205} \mathrm{TI} /{ }^{203} \mathrm{TI}$ and lead isotope ratios were not statistically different.

Table 2. Internal and external precision (reported as 2RSD obtained for both sample introduction system and skimmer cones).

\begin{tabular}{|c|c|c|c|c|c|c|c|c|}
\hline \multirow{2}{*}{$\begin{array}{l}\text { Introduction } \\
\text { system }\end{array}$} & \multirow{2}{*}{$\begin{array}{l}\text { Skimmer } \\
\text { Cone Type }\end{array}$} & \multirow{2}{*}{$\begin{array}{c}\mathrm{Pb} \text { and } \mathrm{Tl} \\
\text { conc. } \\
\left(\mu \mathrm{g} \mathrm{L}^{-1}\right)\end{array}$} & \multicolumn{3}{|c|}{ Internal precision (\%) } & \multicolumn{3}{|c|}{ External precision (\%) } \\
\hline & & & ${ }^{208} \mathrm{~Pb} /{ }^{206} \mathrm{~Pb}$ & ${ }^{207} \mathrm{~Pb} /{ }^{206} \mathrm{~Pb}$ & ${ }^{205} \mathrm{Tl} /{ }^{203} \mathrm{TI}$ & ${ }^{208} \mathrm{~Pb} /{ }^{206} \mathrm{~Pb}$ & ${ }^{207} \mathrm{~Pb} /{ }^{206} \mathrm{~Pb}$ & ${ }^{205} \mathrm{TI} /{ }^{203} \mathrm{TI}$ \\
\hline Conventional & $x$ & 15 & 0.008 & 0.007 & 0.009 & 0.007 & 0.009 & 0.010 \\
\hline
\end{tabular}




\begin{tabular}{|l|l|l|l|l|l|l|l|l|}
\hline & $\mathrm{H}$ & 60 & 0.007 & 0.007 & 0.009 & 0.006 & 0.007 & 0.011 \\
\hline \multirow{2}{*}{ hTISIS } & $\mathrm{X}$ & 10 & 0.007 & 0.007 & 0.008 & 0.008 & 0.007 & 0.008 \\
\cline { 2 - 9 } & $\mathrm{H}$ & 40 & 0.010 & 0.007 & 0.008 & 0.005 & 0.005 & 0.009 \\
\hline
\end{tabular}

As is already known, a reduction of analyte concentration degrades the isotope ratio precision. Figure 2 shows the influence of the $\mathrm{Pb}$ concentration on the ${ }^{208} \mathrm{~Pb} /{ }^{206} \mathrm{~Pb}$ ratio in standard solutions prepared in $100 \%$ ethanol with the hTISIS (at $125^{\circ} \mathrm{C}$ ) and with the conventional sample introduction system, both with the X-type skimmer cone (higher sensitivity without compromising precision compared to H-type skimmer cone). The accuracy and precision of the isotope ratio at different lead concentrations can be estimated from the average value and the relative standard deviation for three measurement replicates of NIST-Pb in an SSB approach. In terms of precision, the hTISIS provided better results than did the conventional sample introduction system at low $\mathrm{Pb}$ concentration (see Figure 2), due to the sensitivity enhancement provided by this total sample consumption system. Additionally, the standard deviation was similar at all concentrations $>2 \mu \mathrm{g} \mathrm{L}^{-1}$ with the hTISIS, whereas it increased significantly at concentrations $<10 \mu \mathrm{g} \mathrm{L}^{-1}$ in case of the conventional sample introduction system. Based on these results, it can be concluded that the lowest $\mathrm{Pb}$ concentration required for obtaining precise lead isotope ratios in $100 \%$ ethanol matrix was $2 \mu \mathrm{g} \mathrm{L}^{-1}$ for the hTISIS operated at $125^{\circ} \mathrm{C}$ and $10 \mu \mathrm{g} \mathrm{L}^{-1}$ for the conventional sample introduction system.

When using the $\mathrm{H}$-type skimmer cone, the minimum concentration of $\mathrm{Pb}$ required to obtain precise lead isotope ratios in a $100 \%$ ethanol matrix is about $15 \mu \mathrm{g} \mathrm{L}^{-1}$ for the hTISIS and and 25 $\mu \mathrm{g} \mathrm{L^{-1 }}$ for the conventional sample introduction system. Moreover, for both types of skimmer cone, the minimum $\mathrm{Pb}$ concentration required remains constant for any ethanol-water ratio in case of hTISIS, whereas it increases with the water content in case of the conventional sample introduction system (see Figure 1). 

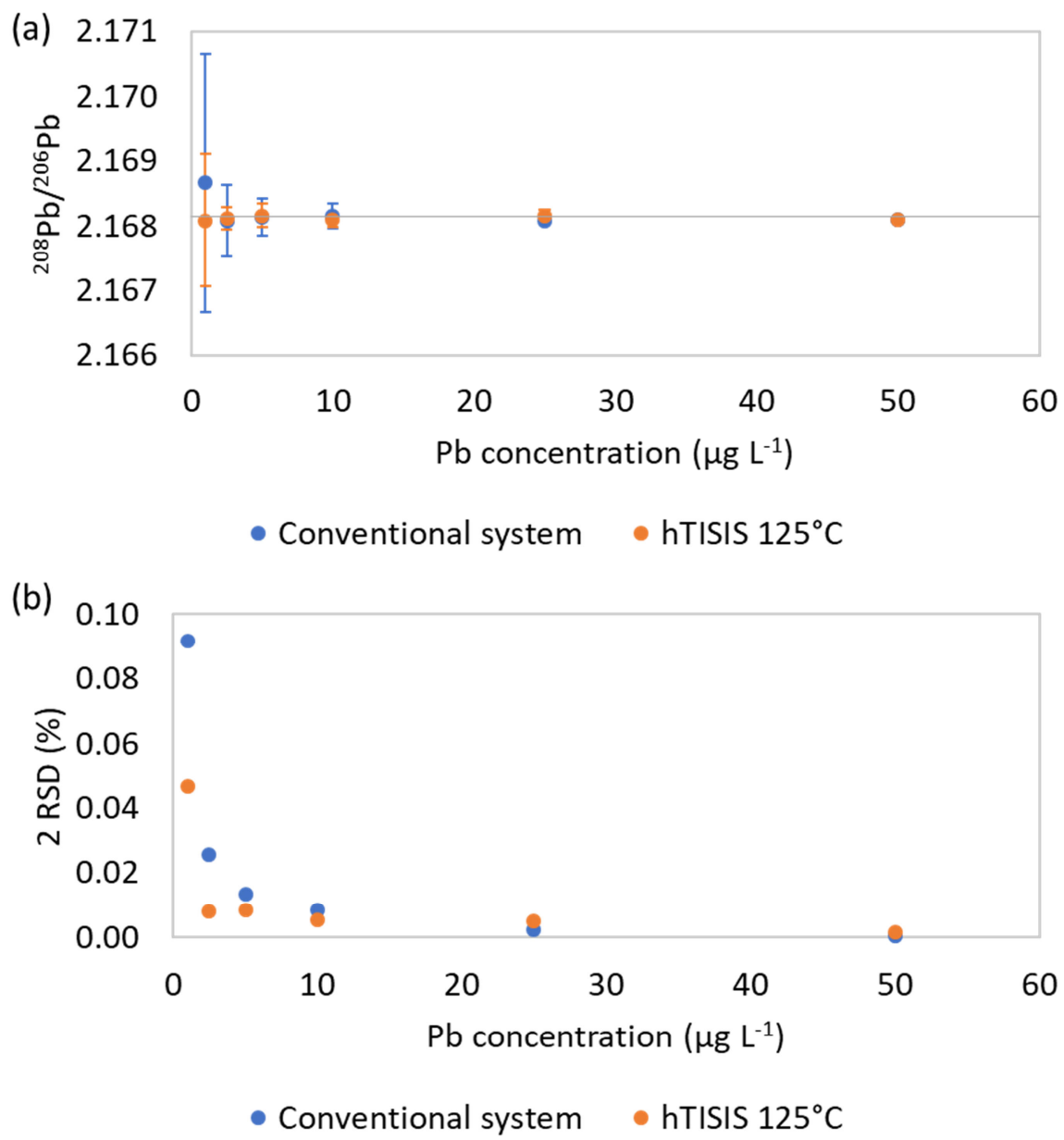

Figure 2. Effect of lead concentration on accuracy and precision (H-type skimmer). (a) ${ }^{208} \mathrm{~Pb} /{ }^{206} \mathrm{~Pb}$ ratios for NIST-Pb. Error bars represent $\pm 2 \mathrm{~s}\left(\mathrm{n}=3\right.$ ). (b) RSD (\%) for the ${ }^{208} \mathrm{~Pb} /{ }^{206} \mathrm{~Pb}$ ratio results plotted in Figure 2.a. Matrix: $100 \%$ ethanol.

\subsection{Effect of sample introduction system and skimmer type on the mass bias correction.}

Different approaches for correction for instrumental mass discrimination were evaluated for different ethanol-water matrices, always using a standard in $75 \%$ ethanol for external correction of any ethanol-water mixture, as detailed in section 2.3. The different mass-bias correction methods, all based on internal correction relying on the use of $\mathrm{Tl}$ as an internal standard followed by external correction in an SSB approach did not provide results showing statistical differences and, finally, the Russell's law (followed by SSB) was relied on for correction of instrumental mass discrimination. ${ }^{16}$ Figure 3 provides corrected lead isotope ratios obtained for all of the ethanolic matrices (concentrations between 10 and $100 \%$ of ethanol), and for the four combinations of sample introduction system/interface (Figure 3).

The mass spectrometer interface plays an important role in the phenomenon of mass discrimination. ${ }^{41}$ With the H-type skimmer cone, mass bias correction, relying on Russell's law (NIST-TI) followed by SSB (NIST-Pb prepared in 75\% ethanol), was found to be adequate for ethanol-water mixtures containing from 10 to $100 \%$ and from 30 to $100 \%$ of ethanol for the conventional sample introduction system and the hTISIS, respectively. However, as indicated in 
previous sections, the sensitivity is strongly deteriorated when using the H-type skimmer cone, which means that this setup is less suited for lead isotopic analysis of bioethanol samples, since the concentration of the target analyte is generally lower than $3 \mu \mathrm{g} \mathrm{L}^{-1}$. As shown in section 3.2, the minimum concentration required for obtaining accurate and precise lead isotope ratios using this skimmer cone type is $15 \mu \mathrm{g} \mathrm{L}^{-1}$ for the hTISIS and $25 \mu \mathrm{g} \mathrm{L}^{-1}$ for the conventional sample introduction system, respectively.

Thus, the use of the X-type skimmer cone is advisable for obtaining reliable lead isotope ratio measurements at low concentration levels $\left(2 \mu \mathrm{g} \mathrm{L}^{-1}\right.$ of $\left.\mathrm{Pb}\right)$. However, it was found that the combination of X-type skimmer cone and cyclonic spray chamber did not enable adequate correction for mass bias, unless in the case of a close matrix-matching, i.e., when the ethanol content of standards and samples is approximately the same (see Figure 3 ). The $\mathrm{Pb}$ isotope ratios obtained for almost all of the ethanol-water mixtures were statistically different from the certified value for NIST-Pb. Only for samples with an ethanol content between 70 and $90 \%$, the ${ }^{208} \mathrm{~Pb} /{ }^{206} \mathrm{~Pb}$ ratio was not significantly different from the certified value. It has been suggested before that the X-type skimmer cone geometry is associated with additional contributions to the instrumental mass fractionation, thus requiring a closer concentrationmatching of sample and standard solutions. ${ }^{41}$ It could therefore be concluded that the influence the ethanol content exerts on the mass bias prevents adequate correction for mass bias using internal correction relying on admixed TI standard (NIST-TI), followed by the SSB approach with a NIST-Pb in $75 \%$ ethanol when using the conventional sample introduction system.

In contrast, when using the hTISIS at $125^{\circ} \mathrm{C}$ combined with the X-type skimmer, the effect of the ethanol content on the extent of mass discrimination did not prevent adequate correction in a range from 60 to $100 \%$ of ethanol. It should be noted that for bioethanol samples after the first distillation step, a water content higher than $40 \%$ is not expected. Thus, based on (i) the improvement in sensitivity and (ii) the possibility to adequately correct for the mass bias in the range of 60 to $100 \%$ of ethanol, the combination of hTISIS and X-type skimmer was selected as the most suitable setup to accomplish $\mathrm{Pb}$ isotopic analysis of bioethanol samples. 


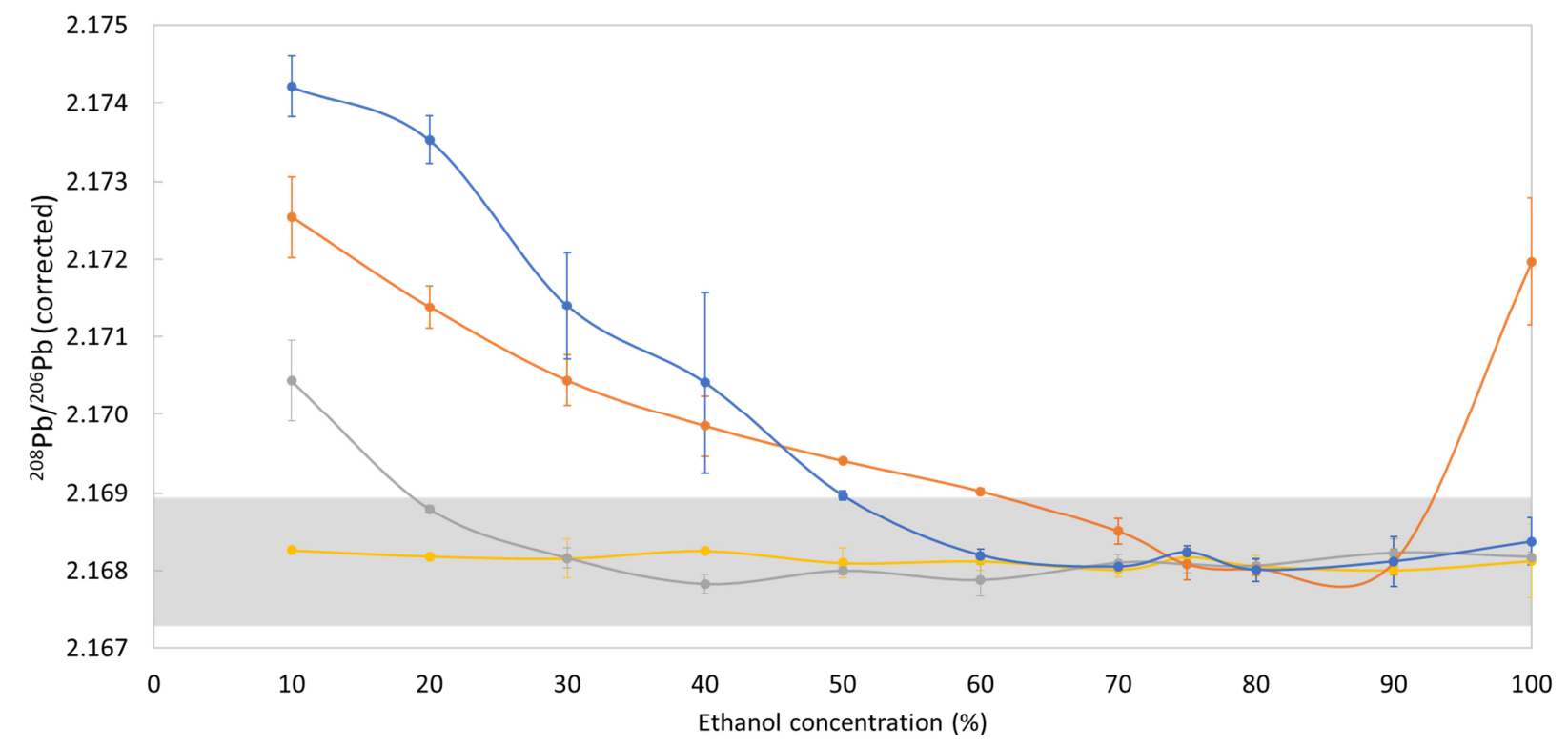

$\rightarrow$ Conventional $+\mathrm{H}$-type skimmer $\rightarrow$ hTISIS $125^{\circ} \mathrm{C}+\mathrm{H}$-type skimmer $\rightarrow$-Conventional $+\mathrm{X}$-type skimmer $\rightarrow$-hTISIS $125^{\circ} \mathrm{C}+\mathrm{X}$-type skimmer

Figure 3. Effect of the matrix composition on the effectiveness of mass bias correction via a combination of internal correction (based on admixed $\mathrm{Tl}$ ) and external correction using $\mathrm{a} \mathrm{Pb}$ standard solution in $75 \%$ ethanol for the different skimmer types and sample introduction systems under optimum conditions. Error bars represent $\pm 2 s(n=3)$. The shaded area shows the certified ratio \pm confidence level.

\subsection{Effect of hTISIS temperature on the mass bias correction}

The temperature at which the hTISIS is operated is a relevant parameter, as has been previously observed for elemental ${ }^{12,13,29,30}$ and isotopic analyses. ${ }^{31-33}$ The hTISIS temperature was optimized for ethanol-water mixtures representative for actual bioethanol samples, i.e., with an ethanol content from 60 to $100 \%$ while using the X-type skimmer. The ${ }^{208} \mathrm{~Pb} /{ }^{206} \mathrm{~Pb}$ ratios obtained upon combined internal (NIST-TI) and external (NIST-Pb in 75\% ethanol) correction are shown in Figure 4 for the different temperatures studied: room temperature (Figure 4.b), $75^{\circ} \mathrm{C}$ (Figure 4.c), $125^{\circ} \mathrm{C}$ (Figure 4.d), $200^{\circ} \mathrm{C}$ (Figure 4.e) and $250^{\circ} \mathrm{C}$ (Figure 4.f). The results were also compared with those obtained with the conventional sample introduction system working at room temperature (Figure 4.a).

It can be observed that, within the ethanol concentration range evaluated (60 - 100\%), the mass bias is not completely corrected for, neither with the conventional sample introduction system (Figure 4.a), nor with the hTISIS at temperatures lower than $125^{\circ} \mathrm{C}$ (Figure $4 . \mathrm{b}$ and Figure 4.c). This can be explained by differences in transport efficiency for different ethanolwater matrices. This hypothesis is in agreement with the partial mitigation of the effect of the ethanol concentration on the extent of mass bias as observed when the hTISIS is heated from room temperature (Figure 4.b) to $75^{\circ} \mathrm{C}$ (Figure 4.c). In addition, the $\mathrm{Pb}$ isotope ratio precision is deteriorated with the hTISIS in comparison with the conventional sample introduction system, when the hTISIS is operated at temperatures lower than $125^{\circ} \mathrm{C}$, which can be related to 
sudden evaporation of ethanol droplets impacting on the chamber walls at lower temperatures.

As has been demonstrated (see section 3.3), when the hTISIS was heated to $125^{\circ} \mathrm{C}$, the mass bias could be adequately corrected for in the range of interest (60-100\% of ethanol) using a single $\mathrm{Pb}$ standard in $75 \%$ ethanol for external correction and good precision was achieved (Figure 4.d). Under these conditions, the transport efficiency is virtually the same, independent of the ethanol concentration.

Finally, an increase of the hTISIS temperature above $125^{\circ} \mathrm{C}$ (Figure 4.e and Figure 4.f) resulted in a degradation of lead isotope ratio accuracy and, especially, in isotope ratio precision. It is hypothesized that further heating of the aerosol does not affect the transport efficiency, but is having a negative effect on the plasma stability thus giving rise to an increase in the signal noise.

All these observations are in agreement with the trends in sensitivity. The intensity was matrixdependent when the hTISIS was operated at temperatures lower than $125^{\circ} \mathrm{C}$, being this effect more pronounced at room temperature than at $75^{\circ} \mathrm{C}$. However, the sensitivity obtained for hTISIS temperatures $\geq 125^{\circ} \mathrm{C}$ was found to be the same for standards containing between $60 \%$ and $100 \%$ of ethanol. In addition, the optimum sensitivity was obtained at $125^{\circ} \mathrm{C}$, reaching a plateau
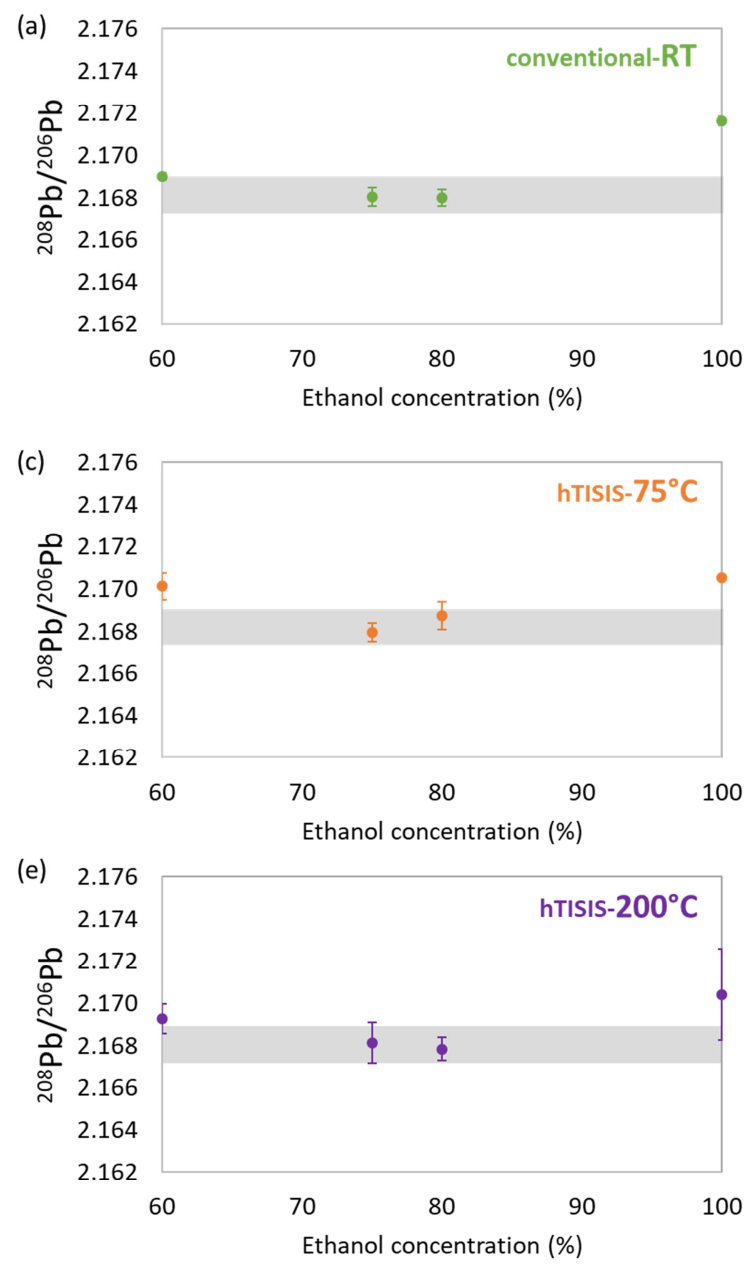

this

temperature.
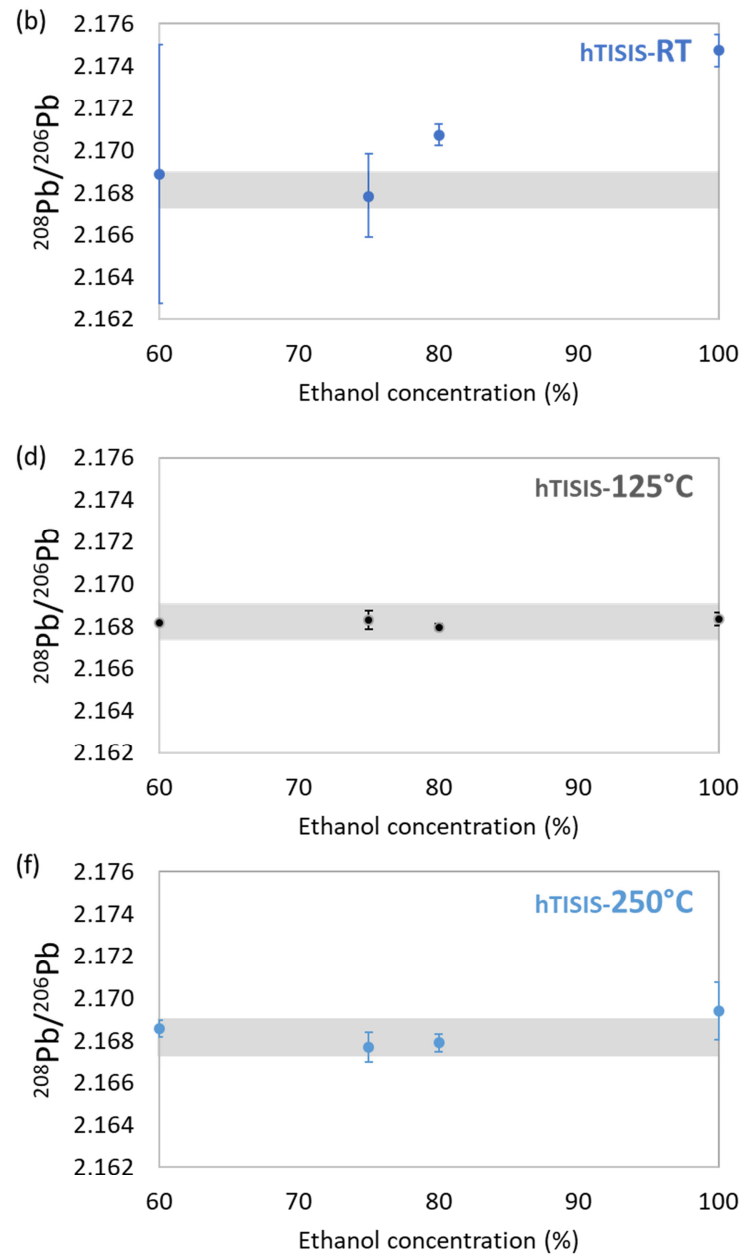
Figure 4. Effect of hTISIS temperature on the effectiveness of mass bias correction. (a) Cyclonic spray chamber at RT (Ref. system), (b)-(f) h-TISIS at (b) RT, (c) $75^{\circ} \mathrm{C}$, (d) $125^{\circ} \mathrm{C}$, (e) $200^{\circ} \mathrm{C}$, and (f) $250^{\circ} \mathrm{C}$. Error bars represent $\pm 2 \mathrm{~s}(\mathrm{n}=3)$. The shaded area represents the certified ratio \pm confidence level.

\subsection{Robustness of the method to real matrices}

For method validation, seven bioethanol samples produced from four different raw materials and containing different water contents ranging from 0 to 30\% ( 100 to 70\% ethanol) and a commercial ethanol sample (96\%, analytical grade), all containing $<0.025 \mu \mathrm{g} \mathrm{L}^{-1}$ of Pb (method detection limit for lead quantification - MDL) were used. It needs to be further stressed that the water content in bioethanol samples is unknown under normal conditions. The samples were spiked with $5 \mu \mathrm{g} \mathrm{L}^{-1}$ of $\mathrm{IH}-\mathrm{Pb}$ standard solution and subsequently measured for their $\mathrm{Pb}$ isotopic composition using MC-ICP-MS with the hTISIS operated at $125^{\circ} \mathrm{C}$ and the X-type skimmer cone. As $\mathrm{Pb}$ was present in the bioethanol samples selected at ultra-trace concentration levels ( $<\mathrm{MDL}$ ), no "blank" subtraction was performed because its effect on the lead isotope ratios was considered negligible within the precision attainable.

The results were plotted versus the reference value for the $\mathrm{IH}-\mathrm{Pb}$ standard solution, previously characterized isotopically $\left({ }^{208} \mathrm{~Pb} /{ }^{206} \mathrm{~Pb}=2.17616 \pm 0.00019,{ }^{207} \mathrm{~Pb} /{ }^{206} \mathrm{~Pb}=0.92331 \pm 0.00006\right)$. Figure 5 shows the ${ }^{208} \mathrm{~Pb} /{ }^{206} \mathrm{~Pb}$ ratio for the eight matrices spiked with $5 \mu \mathrm{g} \mathrm{\textrm {L } ^ { - 1 }}$ of the $\mathrm{IH}-\mathrm{Pb}$ standard solution. The $\mathrm{Pb}$ isotope ratio data obtained were found to be in good agreement with the reference value and no significant differences were observed, neither among the individual results, nor between any of these results and the certified value. Thus, the use of the hTISIS operated at $125^{\circ} \mathrm{C}$ for sample introduction into the MC-ICP-MS unit equipped with the $\mathrm{X}$-type skimmer cone, is a reliable approach for the direct isotopic analysis of lead in bioethanol samples.

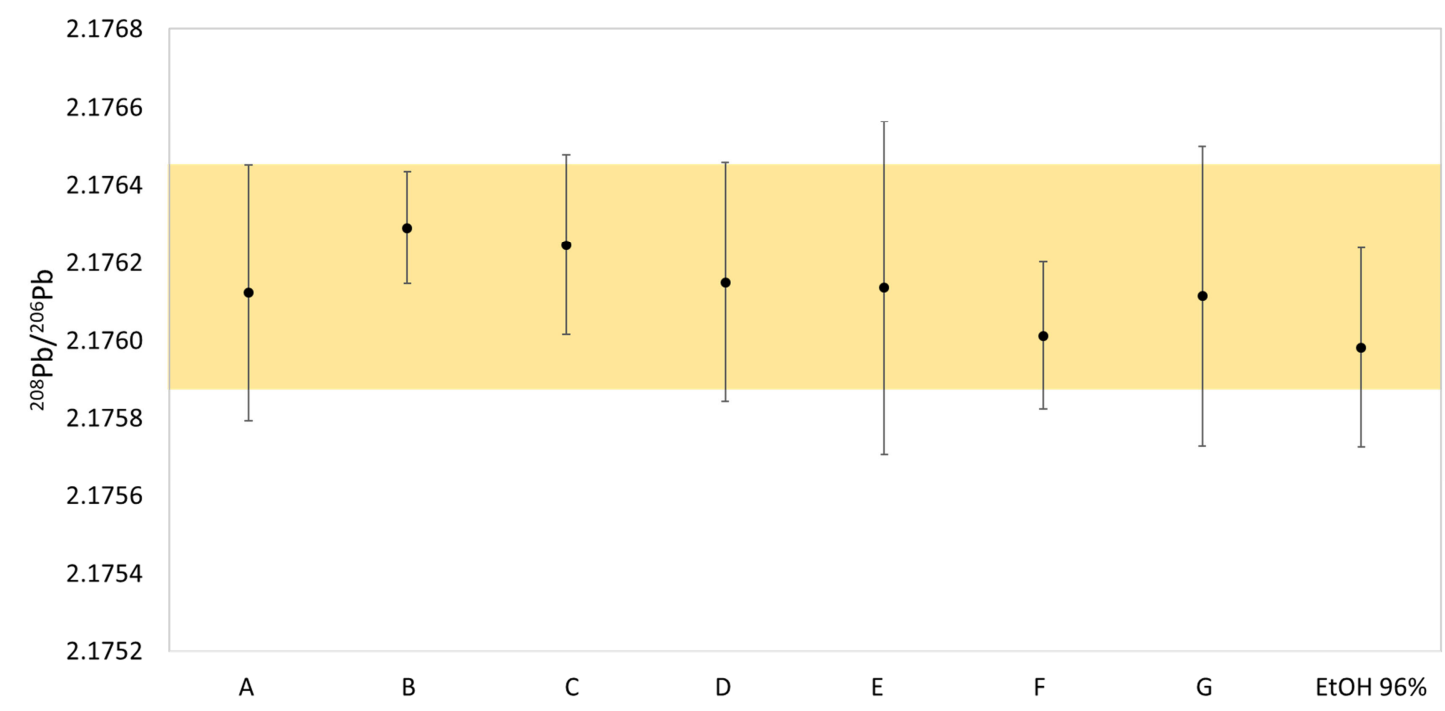

Figure $5 .{ }^{208} \mathrm{~Pb} /{ }^{206} \mathrm{~Pb}$ ratio obtained for spiked bioethanol and ethanol samples with $5 \mu \mathrm{g} \mathrm{L}{ }^{-1}$ of $\mathrm{IH}-\mathrm{Pb}$. Error bars represent $\pm 2 \mathrm{~s}(\mathrm{n}=3)$. The shaded area indicates the reference value \pm confidence level. 


\subsection{Lead isotope ratios in bioethanol}

As a proof of concept, ${ }^{208} \mathrm{~Pb} /{ }^{206} \mathrm{~Pb}$ and ${ }^{207} \mathrm{~Pb} /{ }^{206} \mathrm{~Pb}$ isotope ratios were determined in six real bioethanol samples manufactured from diverse raw materials and containing different water contents (from approximately 0 to $30 \%$ of water). The isotope ratio measurements were performed directly in the bioethanol samples without any sample pre-treatment i.e., without sample digestion and/or analyte isolation, and by using the hTISIS operated under optimum conditions $\left(125^{\circ} \mathrm{C}\right)$ and with the $\mathrm{X}$-type skimmer cone.

$\mathrm{Pb}$ concentrations in the bioethanol samples ranged from 0.8 to $2.5 \mu \mathrm{g} \mathrm{L}^{-1}$. For three of the samples, the $\mathrm{Pb}$ concentration was lower than $2 \mu \mathrm{g} \mathrm{L}^{-1}$, and thus, these samples were preconcentrated by evaporation at room temperature for reaching the minimum concentration required to carry out precise and accurate lead isotope ratios measurement (see section 3.2). It must be ensured that the ethanol content is higher than $60 \%$ after the preconcentration step.

In Figure 6, the data obtained for the bioethanol samples are presented in a three-isotopes plot $\left({ }^{207} \mathrm{~Pb} /{ }^{206} \mathrm{~Pb} v{ }^{208} \mathrm{~Pb} /{ }^{206} \mathrm{~Pb}\right)$. All of the bioethanol samples showed a lighter lead isotopic composition than did the NIST-Pb and IH-Pb standards. ${ }^{208} \mathrm{~Pb} /{ }^{206} \mathrm{~Pb}$ and ${ }^{207} \mathrm{~Pb} /{ }^{206} \mathrm{~Pb}$ ratios in the samples ranged from $2.1024 \pm 0.0013$ to $2.1389 \pm 0.0008$ and from $0.8635 \pm 0.0010$ to 0.8927 \pm 0.0006 , respectively. These ratios are similar to those reported in the literature for wine and other alcoholic beverages coming from fermentation and distillation processes. ${ }^{42,43}$

The second-generation bioethanol sample showed a heavier $\mathrm{Pb}$ isotopic composition than the other samples (first generation biofuel). Additionally, differences were observed between samples coming from different raw materials.

Several reasons could explain the results obtained: (i) $\mathrm{Pb}$ isotope ratios are governed by the corresponding ratios in the raw material and consequently, by the lead isotopic composition of the soil where this material grows and/or by that of airborne deposition ${ }^{24,44-46}$. (ii) It should also be verified whether the $\mathrm{Pb}$ isotopic composition is modified during some steps of the biomass processing to convert it in bioethanol (i.e., syrups extraction and purification, fermentation and distillation), as already demonstrated for metallurgical processes involving heating steps at moderate temperatures ${ }^{47,48}$. (iii) Finally, it should also be taken into account that the lead in the final bioethanol product could be a combination of different lead sources. Recent studies suggested however that the main source of lead in bioethanol is the raw material and that the samples are not polluted during the production process. ${ }^{49}$ In any case, further work is required to elucidate the sources of the lead isotopic variability in bioethanol.

However, these first results suggest that $\mathrm{Pb}$ isotopic analysis could be valuable in the field of biofuels for traceability purposes and for establishing the raw material used for their preparation and/or their provenance. In this work, the geographic origin of the samples was unknown and thus, further research is required for evaluating the potential of $\mathrm{Pb}$ isotopic analysis for provenancing purposes in this context. 


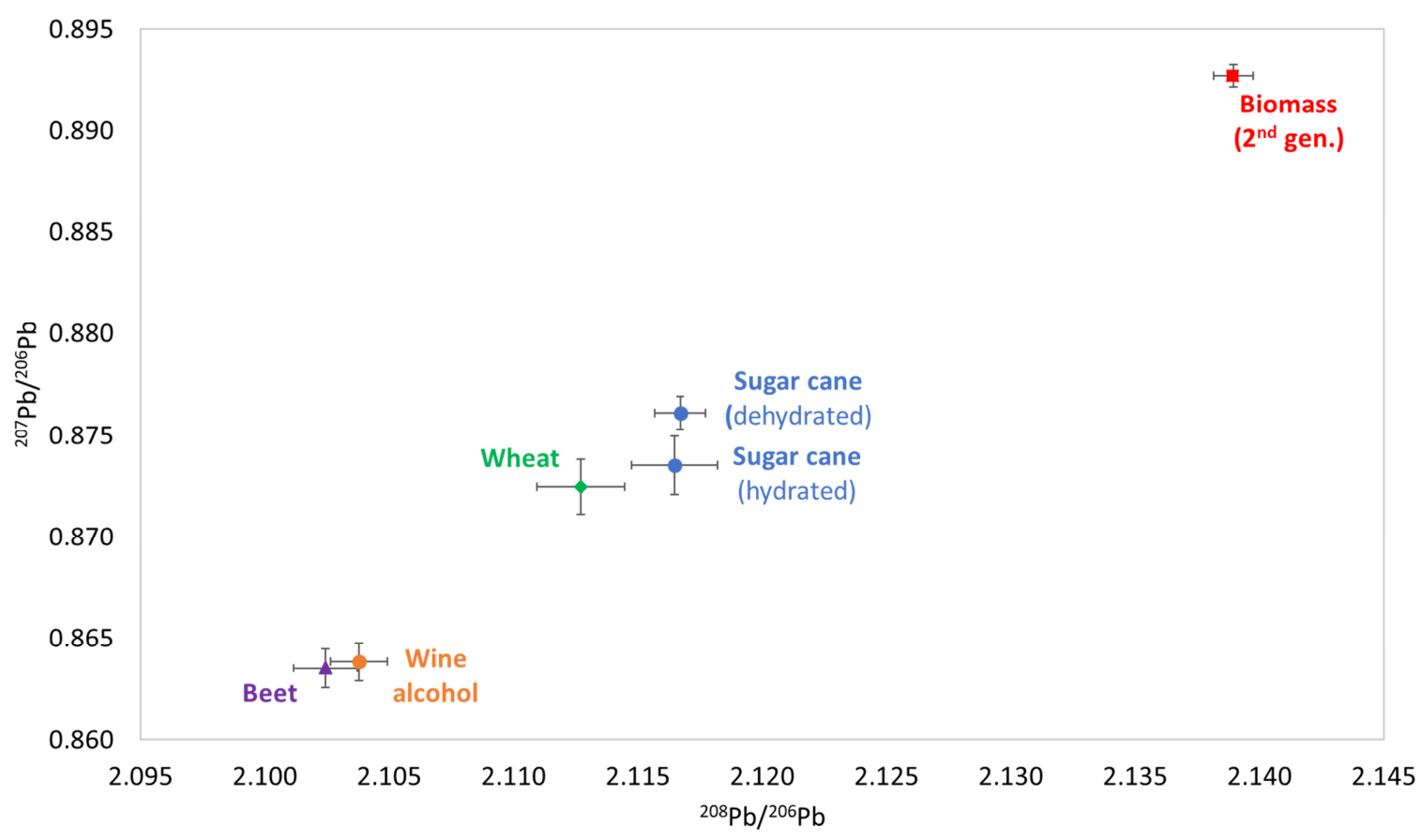

Figure 6. Three-isotopes plot for bioethanol samples coming from different raw materials. Error bars represent \pm 2 s.

\section{Conclusions}

A novel analytical method has been developed for the direct $\mathrm{Pb}$ isotopic analysis of bioethanol samples via hTISIS-MC-ICP-MS, without laborious sample preparation and/or analyte isolation. The hTISIS showed to be advantageous compared to the conventional sample introduction system. The use of hTISIS operated at $125^{\circ} \mathrm{C}$ in combination with the use of a Pt X-type skimmer cone was found to offer the best conditions for $\mathrm{Pb}$ isotopic analysis of bioethanol samples with different ethanol concentrations.

Additionally, a close matrix matching was demonstrated not to be necessary as the instrumental mass bias can be adequately corrected for by using a combination of internal correction using a TI internal standard, relying on the Russell's law, followed by external correction using a $\mathrm{Pb}$ standard in $75 \%$ ethanol in an SSB approach.

This approach is suitable for direct $\mathrm{Pb}$ isotopic analysis of bioethanol samples with a water content up to $40 \%$. It provides accurate $\mathrm{Pb}$ isotope ratios at concentrations $>2 \mu \mathrm{g} \mathrm{L}^{-1}$ with a precision that is similar to those reported in previous papers (use of conventional sample introduction system). The isotope ratios obtained for the spiked bioethanol samples agreed well with the reference value.

As a proof of concept, $\mathrm{Pb}$ isotopic analysis of bioethanol samples coming from different raw materials and of unknown geographical origin revealed significant differences. Thus, the combination of the hTISIS with the MC-ICP-MS opens up new applications for the direct isotopic analysis of biofuel samples for traceability purposes and for obtaining additional 
information on their origin, the raw material employed for manufacturing and processes occurring during their global processing.

\section{Acknowledgements}

The authors wish to acknowledge IFPEN and UNGDA for the samples provided. Carlos Sánchez thanks the Ministry of Education, Culture and Sports, Spain for the contract FPU 13/01438 and the mobility grant EST16/00433 and IFPEN for financial support. Marta Costas-Rodríguez thanks FWO-Vlaanderen for her postdoctoral grant. Eduardo Bolea-Fernandez thanks BOFUGent for his postdoctoral grant. 


\section{References}

1 A. Demirbas, Appl. Energy, 2011, 88, 17-28.

2 M. Köpke and P. Dürre, in Handbook of biofuels production: processes and technologies, Woodhead Publishing Limited, 2011, pp. 221-257.

3 G. M. Walker, Bioethanol: Science and technology of fuel alcohol, Ventus Publishing ApS, 2010.

4 R. Sánchez, C. Sánchez, C.-P. Lienemann and J.-L. Todolí, J. Anal. At. Spectrom., 2015, 30, 64-101.

5 F. Monot, A. Margeot, B. Hahn-Hägerdal, J. Lindstedt and R. Slade, Oil Gas Sci. Technol. -Rev. d'IFP Energies Nouv., 2013, 68, 693-705.

6 P. S. Nigam and A. Singh, Prog. Energy Combust. Sci., 2011, 37, 52-68.

7 P. Lemos and F. C. Mesquita, in Global Bioethanol, Elsevier Inc., 2016, pp. 221-237.

8 J. Fargione, J. Hill, D. Tilman, S. Polasky and P. Hawthorne, Science (80-. )., 2008, 319, $1235-1238$.

9 D. P. Ho, H. H. Ngo and W. Guo, Bioresour. Technol., 2014, 169, 742-749.

10 ASTM International, ASTM D4806-16a, Standard Specification for Denatured Fuel Ethanol for Blending with Gasolines for Use as Automotive Spark-Ignition Engine Fuel, West Conshohocken, 2016.

11 ABNT - Associação Brasileira de Normas Técnicas, ABNT NBR 11331-Ethyl alcoholDetermination of iron and copper concentrations - Atomic absorption spectrophotometry method., 2007. C. Sánchez, C.-P. Lienemann and J.-L. Todolí, Spectrochim. Acta Part B At. Spectrosc., 
2016, 115, 16-22.

13

C. Sánchez, C.-P. Lienemann and J.-L. Todolí, Spectrochim. Acta Part B At. Spectrosc., 2016, 124, 99-108.

14 M. F. Thirlwall, Chem. Geol., 2002, 184, 255-279.

15 C. Deniel and C. Pin, Anal. Chim. Acta, 2001, 426, 95-103.

16 L. Yang, Mass Spectrom. Rev., 2009, 28, 990-1011.

17 I. Günther-Leopold, B. Wernli, Z. Kopajtic and D. Günther, Anal. Bioanal. Chem., 2004, $378,241-249$.

18 F. Guéguen, A. Nonell, H. Isnard, L. Vio and F. Chartier, Talanta, 2017, 162, 278-284.

19 J. Woodhead, J. Anal. At. Spectrom., 2002, 17, 1381-1385.

20 D. C. Baxter, I. Rodushkin, E. Engström and D. Malinovsky, J. Anal. At. Spectrom., 2006, 21, 427.

21 V. Devulder, L. Lobo, K. Van Hoecke, P. Degryse and F. Vanhaecke, Spectrochim. Acta Part B At. Spectrosc., 2013, 89, 20-29.

22 F. Vanhaecke, L. Balcaen and D. Malinovsky, J. Anal. At. Spectrom., 2009, 24, 863.

23 L. Balcaen, L. Moens and F. Vanhaecke, Spectrochim. Acta- Part B At. Spectrosc., 2010, 65, 769-786.

24 C. Reimann, B. Flem, K. Fabian, M. Birke, A. Ladenberger, P. Négrel, A. Demetriades, J. Hoogewerff and The GEMAS Project Team, Appl. Geochemistry, 2012, 27, 532-542.

25 P. Vallelonga, P. Gabrielli, E. Balliana, A. Wegner, B. Delmonte, C. Turetta, G. Burton, F. Vanhaecke, K. J. R. Rosman, S. Hong, C. F. Boutron, P. Cescon and C. Barbante, Quat. Sci. Rev., 2010, 29, 247-255. 
27 S. Dreyfus, C. Pecheyran, C. P. Lienemann, C. Magnier, A. Prinzhofer and O. F. X. Donard, J. Anal. At. Spectrom., 2007, 22, 351-360. Spectrom., 2014, 29, 242-248. 27, 937.

31 E. Paredes, D. G. Asfaha and C. R. Quétel, J. Anal. At. Spectrom., 2013, 28, 320.

32 E. Paredes, J. L. Todoli and C. R. Quétel, J. Anal. At. Spectrom., 2013, 28, 327.

33 A. Bazzano, K. Latruwe, M. Grotti and F. Vanhaecke, J. Anal. At. Spectrom., 2015, 30, $1322-1328$.

34 A. Bazzano and M. Grotti, J. Anal. At. Spectrom., 2014, 29, 926.

35 E. Paredes, D. G. Asfaha, E. Ponzevera, C. Brach-Papa, M. Van Bocxstaele, J. L. Todolì, C. R. Quetel, J. L. Todolí and C. R. Quétel, J. Anal. At. Spectrom., 2011, 26, 1372-1379. Spectrosc., 2013, 88, 104-126.

38 K. De Wolf, L. Balcaen, E. Van De Walle, F. Cuyckens and F. Vanhaecke, J. Anal. At. Spectrom., 2010, 25, 419.

39 T. D. Saint'Pierre, L. Tormen, V. L. Frescura and A. J. Curtius, J. Anal. At. Spectrom., 2006, 21, 1340. 
40 S. M. Chernonozhkin, M. Costas-Rodríguez, P. Claeys and F. Vanhaecke, J. Anal. At. Spectrom., 2017, 32, 538-547.

41 K. Newman, J. Anal. At. Spectrom., 2012, 27, 63-70.

42 M. Barbaste, L. Halicz, A. Galy, B. Medina, H. Emteborg, F. C. Adams and R. Lobinski, Talanta, 2001, 54, 307-317.

43 I. Rodushkin, O. Fredrik and P. K. Appelblad, J. food Compos. Anal., 1999, 12, 243-257.

44 Y. Erel, A. Veron and L. Halicz, Geochim. Cosmochim. Acta, 1997, 61, 4495-4506.

45 H. Cheng and Y. Hu, Environ. Pollut., 2010, 158, 1134-1146.

46 R. M. Harrison and M. B. Chirgawi, Sci. Total Environ., 1989, 83, 13-34.

47 P. Budd, A. M. Pollard, B. Scaife and R. G. Thomas, Archaeometry, 1995, 37, 143-150.

48 J. Cui and X. Wu, Archaeometry, 2011, 53, 205-214.

49 C. Sánchez, J.-P. Vidal, C.-P. Lienemann and J.-L. Todolí, Fuel Process. Technol., 2018, $173,1-10$. 